formed and fails to relate the continuous flow of magma through a channel to the observed episodic nature of surface volcanism. One of the rather more sophisticated models has a magma body, or 'bubble', floating upwards through the lithosphere (regarded as a highly viscous fluid); but the thermal requirements of this process have not yet been worked out. Whatever the problems may be here, however, flow through the lithosphere can only occur if the magma reaches the base of that layer in the first place; and it is this initial migration of magma in the asthenosphere (where the magma is produced) which is now the subject of a modelling study by Turcotte and Ahern (J. geophys. Res. 83, 767; 1978).

In the Turcotte-Ahern model the asthenosphere is regarded as a porous medium, the mass being convected within it is assumed to rise at constant velocity, and the material of which it consists is supposed to contain a relatively low melting temperature component. As the mantle material convects upwards towards lower pres-

Peter J. Smith is a Reader in the Department of Earth Sciences at the Open University. sure regions the lower melting temperature component melts, producing liquid (destined to give basalt at the Earth's surface); the remaining solid deforms to accommodate this liquid, thus producing what is in effect a saturated porous material; and as more liquid is produced it begins to form interconnected channels, thereby providing the material with permeability.

The liquid-produced permeability is central to the model; and Turcotte and Ahern devote much of their mathematical argument to the use of this property in determining the structure of the melting region within which the liquid is produced and in elucidating the relationship between such parameters as mantle ascent velocity; magma viscosity, volume fraction of melt and magma migration velocity. The essential result, however, is that in the permeability model the melt rises much faster than the ascending convective mass. In other words, the permeability arising from partial melting offers a convincing mechanism for magma migration in the asthenosphere. But what happens when that magma reaches the base of the lithosphere is another story.

\title{
Insect/host plant relationships
}

\author{
from a Correspondent
}

INTEREST in insect/host plant relations is rapidly increasing with the general acceptance that pesticides are only a partial palliative against insect pests of crops. A recent symposium* on insect/ host plant relationships was therefore very timely.

One feature of the meeting was the attempt by physiologists and behaviourists to relate their studies closely to the ecology of insects. This was exemplified in the studies on the Colorado beetle, with T. Hsiao (Utah State University) demonstrating differences in food selection between populations from different regions of the United States. Geographically isolated populations showed considerable differences in both host plant affinity, and in adaptability to different species of Solanaceae. The evidence strongly suggests that specific host-adapted populations are developing quite quickly in North America, and that such biotype differences must be preceded initially by geographic isolation. J. H. Visser and W. C. Ma (Agricultural University,

*Held on 4-9 June, 1978 at the Fulmer Grange be published as a supplement to Entomologia Experimentalis et Applicata.
Wageningen) reported on their detailed study on the odour of potato plants and the manner in which the insect can detect and respond to it. Odour from potato plants elicit anemotactic responses in the Colorado beetles, but none of the individual components applied singly is attractive. A mixture of components with the appropriate relative proportions is required to elicit the behavioural response. An analysis of neurophysiological responses from antennal olfactory cells, showed that discrimination of mixtures of plant volatiles is possible on the basis of information from a limited number of receptor types with different sensitivity spectra.

The attendance of a number of plant chemists reflected the recent expansion of interest in phytochemistry and cooperation between chemists and entomologists. G. Cooper-Driver (University of Boston) in discussing the chemical defences in ferns, emphasised the importance of these plants in the evolution of phytophagous insects and the relative paucity of information on insect/fern relationships. The more ancient orders of insects, however, are generally better represented than expected, at least on tropical ferns, suggesting a long association between ferns and these orders in spite of the variety of generally deterrent compounds.

R. Hamilton (Liverpool Polytechnic) discussed the basis of attraction of frit flies to oats and showed that there is a synergistic interaction of a lipid and a non lipid material. The lipid was shown to be a hydroxybetadiketone.

An important development was the greatly increased awareness of the value of an evolutionary approach in understanding the present-day relationships of insects with plants. V. Labeyrie (Francois Rabelais University, Tours) emphasised that the insect/plant relationship was not a simple relationship of an insect with its host, but was influenced by other features of the environment. For example the celery fly which mines in the leaves of Umbelliferae also require trees where the sexes meet and mate and must have envolved in a landscape where the two types of plant coexist. E. A. Bernays (Centre for Overseas Pest Research, London) described experiments which demonstrated the capacity of locusts and grasshoppers to feed without ill effects on plants containing high levels of tannins which are general protein precipitants. She considered that the early phytophagous insects had the capacity to tolerate or counter these chemicals, emphasising the dangers of generalisations based on limited numbers of species.

The long term chronic effects of plant chemicals were discussed by a number of participants. Notable in this respect was the contribution by $\mathbf{J}$. M. Scriber (University of Wisconsin, Madison) with an impressive volume of data on a range of lepidopterous species. From the study of over 700 insects from 22 species, he has shown that consumption rates, conversion efficiencies and hence growth rates of tree feeders were lower than for herbaceous plant feeders. This relationship is at least partially a result of the higher water content of herb leaves.

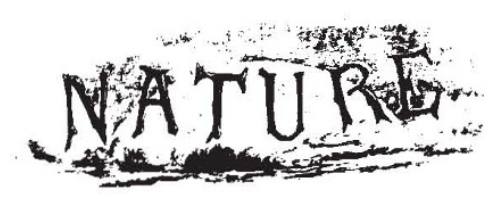

\section{A hundred years ago}

Prof. Virchow has decided to resign his seat in the German parliament. He takes this step solely because his parliamentary duties interfere with his scientific labours; and while he may be a good enough politician, he thinks himself a better savant.

Fromi Nature 18, 11 July, 290; 1878. 